This item was submitted to Loughborough's Research Repository by the author.

Items in Figshare are protected by copyright, with all rights reserved, unless otherwise indicated.

\title{
Incorporating the voice of multiple customers into product design
}

PLEASE CITE THE PUBLISHED VERSION

PUBLISHER

(C) IMechE / Professional Engineering Publishing

VERSION

VoR (Version of Record)

LICENCE

CC BY-NC-ND 4.0

REPOSITORY RECORD

Bamforth, Sarah E., and N.J. Brookes. 2019. "Incorporating the Voice of Multiple Customers into Product Design”. figshare. https://hdl.handle.net/2134/4615. 
This item was submitted to Loughborough's Institutional Repository (https://dspace.lboro.ac.uk/) by the author and is made available under the following Creative Commons Licence conditions.

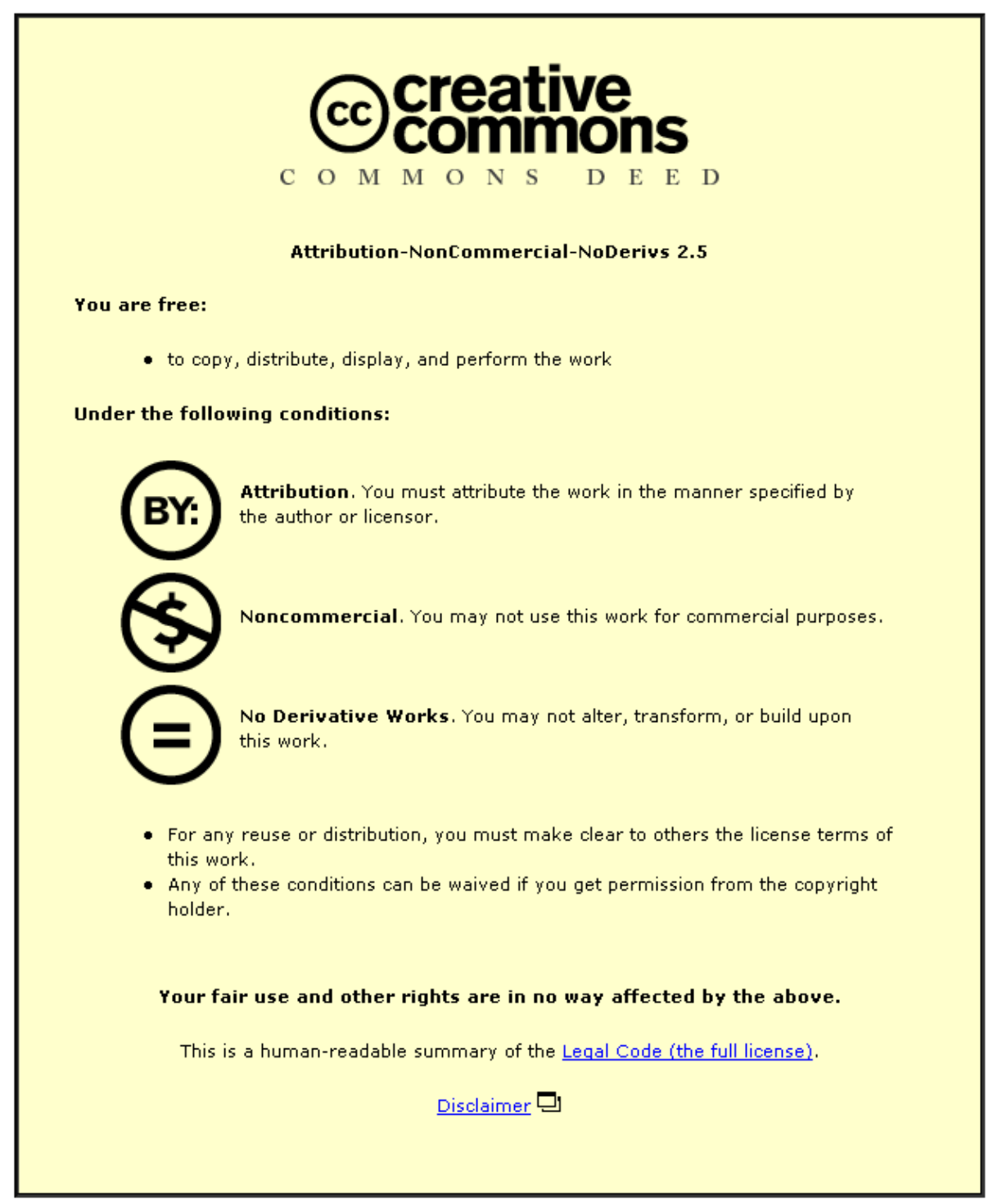

For the full text of this licence, please go to: http://creativecommons.org/licenses/by-nc-nd/2.5/ 


\title{
Incorporating the voice of multiple customers into product design
}

\author{
S Bamforth* and N J Brookes \\ CACTUS Project, Wolfson School of Mechanical and Manufacturing Engineering, Loughborough University, \\ Leicestershire, UK
}

\begin{abstract}
Listening to the voice of the customer is made complicated when the roles of the customer are carried out by more than one individual or stakeholder (a stakeholder performs one or more of the decision-making roles normally enacted by a single customer). The issues surrounding multiple stakeholder requirements are examined with particular reference to small to medium enterprises (SMEs) and the rehabilitation industry; this industry is concerned with products that enable the elderly and disabled to live more independently. A series of case studies has been conducted to identify the current practices of rehabilitation companies and the suitability of accepted design methods for incorporating the voice of the customer into the design process. The results of the study indicate that smaller companies within the rehabilitation industry do not use formal methods of design or market research; this is partly attributable to their limited resources and experience. An outline is given of a method developed by the CACTUS Project to enable resource-limited companies in the rehabilitation industry to incorporate the voice of the customer into their design. The method is currently being tested. It is hoped that the CACTUS approach will be applicable to other industries with similar characteristics and multiple stakeholders.
\end{abstract}

Keywords: multiple stakeholders, voice of the customer, product design, design methodologies

\section{INTRODUCTION}

Small to medium enterprises (SMEs) with multiple stakeholders face the problem of incorporating the voice of multiple customers into the design of a product. The term multiple stakeholder is used to refer to those individuals who collectively perform the decisionmaking roles of the customer. Traditionally the customer is envisaged as a single decision-making entity who carries out the multiple roles of choosing, purchasing, installing and using a product. In reality discrete stakeholders can perform these roles. Listening to the needs of multiple stakeholders requires a company to be able to conduct manifold market research and to consolidate opposing needs. SMEs are often hindered in this activity by their limited resources and experience.

A classic example of an industry with multiple stakeholders is the rehabilitation industry, also known as the assistive technology industry. Assistive technologies are the total of technologies provided directly to elderly

The MS was received on 30 November 2001 and was accepted after revision for publication on 28 February 2002.

* Corresponding author: CACTUS Project, Wolfson School of Mechnical and Manufacturing Engineering, Loughborough University, Loughborough, Leicestershire LE11 3TU, UK. and/or disabled people to enable them to live more independent lives [1]. Rehabilitation products can have as many as five distinct decision-making groups (stakeholders) involved in their direct provision and use. The issue of incorporating the voice of the customer into design has gained significance in this industry as government funded research has revealed the state of rehabilitation equipment as being of poor quality and failing to meet user expectations [2]. Reports also indicate that manufactures have a key role to play in improving quality via customer input into the product design process [3].

The paper reports on the work of the CACTUS Project. The problems faced by the rehabilitation industry, in particular the issue of multiple stakeholders, and a method to enable rehabilitation SMEs to incorporate the voice of its many stakeholders into the design of their products are presented.

\section{CURRENT PRACTICES AND THE SUITABILITY OF STANDARD METHODS}

The rehabilitation industry is characterized by its dominance of small to medium enterprises, its deficiency 
Table 1 Resources and practices of rehabilitation companies

\begin{tabular}{|c|c|c|c|c|c|c|}
\hline Company & $\begin{array}{l}\text { Number of } \\
\text { employees }\end{array}$ & $\begin{array}{l}\text { Product } \\
\text { ranges }\end{array}$ & $\begin{array}{l}\text { Market research } \\
\text { department }\end{array}$ & $\begin{array}{l}\text { Type of } \\
\text { customer input }\end{array}$ & $\begin{array}{l}\text { Use a formal } \\
\text { design approach }\end{array}$ & $\begin{array}{l}\text { Design } \\
\text { teams }\end{array}$ \\
\hline A & 4 & 1 & No & Informal & No & No \\
\hline B & 10 & 8 & No & Informal & No & No \\
\hline $\mathrm{C}$ & 20 & 4 & No & Informal & No & No \\
\hline $\mathrm{D}$ & 278 & 11 & Yes & Formal & Yes & Yes \\
\hline $\mathrm{E}$ & 1000 & $>100$ & Yes & Formal & Yes & Yes \\
\hline
\end{tabular}

of development engineering and managerial skills, a lack of private sector investment, the reliance of firms on a narrow range of products and its multiple stakeholders $[4,5]$. A series of case studies have been conducted by the CACTUS Project to identify the current practices and attitudes of companies in the rehabilitation industry. Five UK companies of varying size were involved in the case study. The chosen companies design and assemble their products, which include bathing aids and seating systems, and the number of product ranges across the companies varies between one and several hundred. The size of company varied between four and one thousand employees.

The case study questioned the companies in regard to the structure and resources of their organization, their product development process and their marketing capabilities. The attitudes of the companies towards benefits offered by formal design approaches were also investigated in order to identify any constraints on a potential solution. Table 1 displays a simplified version of the results obtained regarding the resources of the organizations. Table 1 indicates that the larger companies investigated are able to support formal product development and market research while the small companies are not. The case study indicates that the smaller the company the less formal the market research becomes.

The first three companies listed in Table 1 have neither marketing department nor person(s) for which market research forms part of their job. Conversely, the larger companies both have marketing departments and both practice recognized market research techniques. With regards to the product development process and design approaches used by the companies examined, only the two larger companies were able to produce documented evidence of the processes that they follow. When questioned more fully the smaller companies identified that they do not have a documented design approach, nor do they follow any structured or recognized process and that product design specifications do not form part of their design activity.

Table 2 presents the attitudes of the companies towards the attributes offered by industrially accepted design methods. Of the companies studied, all view increasing customer satisfaction as a very important attribute and all agree that a means of incorporating customer requirements into the product design is important, to a lesser or greater degree. Worthy of note is the desire of the smaller companies to increase their customer satisfaction but their lack of concern with reducing downstream design changes and their unwillingness to conduct competitive benchmarking.

The study reveals that poor product quality is partly attributable to ineffective market research and poorly structured design activities carried out in small companies. With regards to a suitable structure for the design process, the study indicates that an acceptable method or tool must require limited resources and experience to implement and must concur with the attitudes of the companies it is to be used by. Based

Table 2 Attitudes to the characteristics offered by existing 'customer-satisfying' design methods

\begin{tabular}{|c|c|c|c|c|c|}
\hline \multirow[b]{2}{*}{ Attributes } & \multicolumn{5}{|c|}{ Company } \\
\hline & A & $\mathrm{B}$ & $\mathrm{C}$ & $\mathrm{D}$ & $\mathrm{E}$ \\
\hline Incorporates customer requirements & Important & Very important & Very important & Very important & Very important \\
\hline Reduces time to market & Important & Important & Important & Important & Very important \\
\hline Reduces indirect costs & Important & Unimportant & Unimportant & Important & Important \\
\hline Utilizes competitive bench marking & Opposed to & Opposed to & Opposed to & Important & Important \\
\hline Produces documentation & Opposed to & Unimportant & Unimportant & Important & Important \\
\hline $\begin{array}{l}\text { Reduces number of downstream } \\
\text { design changes }\end{array}$ & Unimportant & Important & Unimportant & Very important & Very important \\
\hline $\begin{array}{l}\text { Indicates the appropriate design for } \\
\text { development }\end{array}$ & Important & Unimportant & Unimportant & Important & Unimportant \\
\hline $\begin{array}{l}\text { Utilizes cross-functional team } \\
\text { members }\end{array}$ & Opposed to & Important & Unimportant & Important & Important \\
\hline $\begin{array}{l}\text { Provides a step-by-step development } \\
\text { guide }\end{array}$ & Opposed to & Unimportant & Unimportant & Important & Unimportant \\
\hline
\end{tabular}


upon the results of the case study a specification for a suitable design method for small rehabilitation companies has been drawn up. These requirements are:

1. Enable the development of customer-satisfying products.

2. Require limited marketing and development skills to implement.

3. Act as a guide to the most appropriate marketing method to use for each stakeholder.

4. Enable designers to have a greater understanding of the needs of the customer.

5. Deal with multiple stakeholders effectively.

6. Enable the development of cheap-to-manufacture products.

7. Require limited worker hours to utilize.

8. Structure the problem without restricting the freedom to develop solutions.

9. Provide a cheap and cost effective development process.

The CACTUS Project has previously made a study of the current methods and tools employed across industry that incorporate the voice of the customer into the product development process. These methods include quality function deployment, strategic design, concurrent engineering, requirement trees and total design [6-10]. The appropriateness of these methods has been investigated based on the identified needs of small companies in the rehabilitation industry. The results of this study indicate that while these methods offer many attributes required by rehabilitation companies their other characteristics mean that they are not suitable for direct application to these small companies. Many of these methods are unsuitable due to their resource requirements and because some of their practices are opposed by small companies.

\section{THE CACTUS METHODOLOGY}

In the light of the project's findings a methodology suitable for small companies in the rehabilitation industry has been developed. The CACTUS approach is a collection of tools designed to aid the development of customer-satisfying products. These tools enable the user, with limited resources and experience, to gather, structure and incorporate multiple stakeholder needs into the product development process. The method takes the user through the early stages of a product development activity: from gathering market requirements to developing a product design specification. Many of the ideas used in this design approach have been distilled from recognized methods already employed across a wide range of industries; these include quality function deployment, requirement trees and strategic design.

The CACTUS approach consists of seven tools; the basic outline of six of the tools is shown in Fig. 1. Tools 1 and 2 form phase I of the CACTUS approach: gather requirements. Tool 1 is the market research identifier. This tool aids the user in identifying an appropriate form of market research to undertake depending on the user's resources, the type of stakeholder and the capabilities of the stakeholder. The first half of tool 1 poses a series of questions that concern the company's current capabilities and intended market. Through

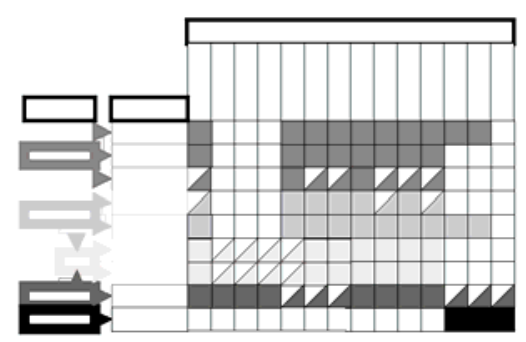

Tool 2

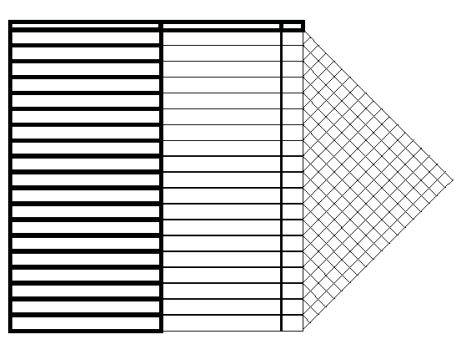

Tool 5

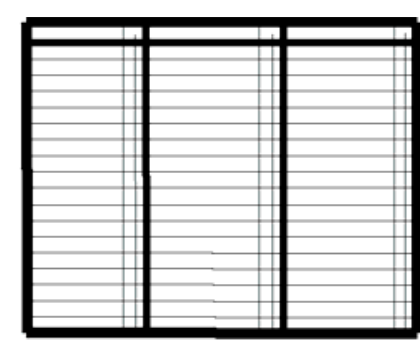

Tool 3

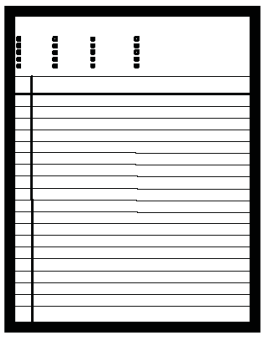

Tool 6

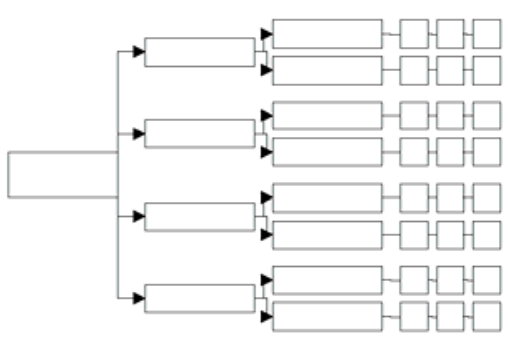

Tool 4

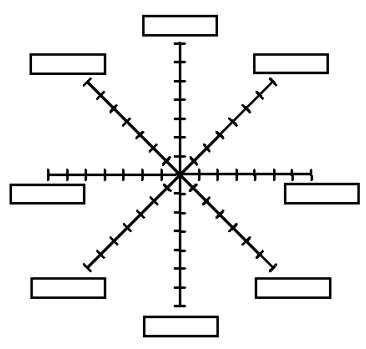

Tool 7

Fig. 1 CACTUS approach tools 
answering these questions the user is able to identify, for that situation, the resources and skills currently available and who to target their research at. The second part of tool 1 consists of market research techniques rated according to the amount of time, manpower and skill they require and for what type of stakeholder situation they are best suited. The ratings are displayed using simple icons to facilitate rapid comparisons. Through the awareness raised in part one of the tool, the most appropriate market research method can be selected for that situation.

Tool 2 is the knowledge source matrix. This tool relates to the core customers involved in rehabilitation products; these can be the end-user, family members, the carer, the medical professional and the financier. The matrix gives the user an indication of who the primary and secondary sources of knowledge are depending on the stakeholder's role. The matrix works by relating product areas, such as aesthetics and function, to stakeholders and their roles. At the intersection of product area and role the matrix visually indicates, through symbols, the status of the stakeholder. The status can be that of either having no knowledge on that subject or being a first- or second-hand knowledge source. Identifying sources of information allows the user to direct market research at the stakeholder appropriate to the area of enquiry. This tool can also be used to gauge how much authority can be given to a stakeholder requirement identified through the market research.

The second phase of the approach is the organize requirements phase. Tool 3 is the theme and characteristic tool. This tool is a low-cost means of rapidly identifying the main themes of the gathered market research. Tool 3 encourages the user to read and note down customer requirements from the research data. The user then groups like requirements and expresses them as a single encapsulating statement of need. The theme and characteristic form allows these statements to be recorded, under the heading of theme, characteristic and other. For each statement a tally is kept of the number of respondents articulating that requirement and the tally is logged, categorizing the respondent as a first- or second-hand knowledge source. The theme and characteristic tool conveys what proportions of the requirements are being articulated by first- and second-hand sources. By using the theme and characteristic form in conjunction with the knowledge source matrix, imperative requirements and areas for further market research are easily identified.

The third and final phase of the approach is the translate requirements phase. Tools 4, 5, 6 and 7 are used in this phase. Tool 4 is the requirement clarification tool. The tool is based upon the requirement tree method. The tool enables the user to break down customer requirements into their constituent meanings, where each branch progressively clarifies an initial statement taken from the theme and characteristic form. A branch terminates when logically a statement cannot be clarified further; the statement is unambiguous, verifiable and often quantified. Through the tool, customer requirements are translated into engineering requirements. The tool builds upon the requirement tree method by allowing the user, by means of scoring, to indicate the feasibility of fulfilling a requirement and the importance of meeting a requirement. Importance is dependent upon the relative value of the stakeholder to the company and the importance of the requirement to the stakeholder.

Tool 5 is the relationship matrix. This method is a cut down version of the house of quality. The tool is comprised of a single triangular matrix that juxtaposes the engineering requirements produced from the previous tool. In order for the relationship matrix tool to be appropriate to the industry, the competitor-comparison component has been removed from the tool. Altering its purpose slightly has further reduced the length of time taken to utilize the tool without loosing its main benefit. The relationship matrix is used to identify the negative relationships that exist between engineering characteristics. This is done in order that resources are not wasted in trying to incorporate features into a product that conflict with other more important features. On the matrix, the original customer requirements and their overall importance rating is displayed alongside their corresponding engineering characteristics. When coupled with the strength of negative relationships being displayed as symbols, these features aid the decision on how to resolve the conflict.

Tool 6 is the product design specification form. Using the output of the relationship matrix the customerrelated portion of the product design specification (PDS) form is simple to fill out. Each page of the specification form relates to issues that must be covered in a PDS. While the purpose of the CACTUS approach is to incorporate the voice of the customer into the design process, tool 6 is designed for, and emphasizes, the need for other issues to be considered in a product design. The PDS form is provided to aid the user in structuring a list of specifications that a solution must meet for the product to be successful.

Tool 7 is the concept footprint; it is derived from the quality chart used in the strategic design method. The footprint tool enables the comparison of conceptual designs, using requirement-based metrics, to aid concept selection. The concept footprint consists of an eightpronged cross; the end of each prong corresponds to a single customer or manufacturing requirement, chosen for its importance by the user. For each concept design the characteristics of that design are plotted on the chart in relation to the extent to which the design meets a specification. These plots are joined in a line forming an angular ring. Minimum and target values are also plotted for each metric. The concept footprint is a very visual tool; a successful concept design will have a footprint whose plot tends towards the target 
line. In addition to aiding the concept selection process, the concept footprint can also be used to note the effect of any design alterations to the shape of the original footprint.

Collectively the seven tools of the CACTUS approach fulfil the previously identified requirements of the rehabilitation industry. All of the tools are designed for use by those with limited resources and experience. The voice of the customer is incorporated into the design process by means of successive tools that translate requirements into engineering specifications. Designs can then be developed from this structured and customer-based platform, increasing the potential for customer-satisfying products. Most importantly, tools 2, 3 and 4 enable resource-limited companies to deal with multiple stakeholder requirements by juxtaposing requirements and emphasizing those requirements that relate to the particular role of the stakeholder.

\section{FUTURE WORK}

The CACTUS approach is currently being tested both within the industry and with designers outside the rehabilitation field. The acceptability of the method to the industry and its success as a tool to quickly and cost effectively design customer-satisfying products are both being examined. The validation process will include the application of the approach to three product design activities, customer focus groups and a workshop with designers from the industry. Initial results from the product design activities are positive. While the content of the knowledge source matrix is unique to the rehabilitation field, it is hoped that the remaining tools that comprise the CACTUS approach will be applicable to other industries with similar characteristics.

\section{REFERENCES}

1 Technological Initiative for Disabled and Elderly Persons (TIDE), 1992 (European Commission, Brussels).

2 Fully Equipped, March 2000 (Audit Commission).

3 Why Should We Care: Best Practice in Disability Equipment Services, Disabled Living Centres Council, 1999 (The Stationary Office, London).

4 Ajimal, K. FINCOM. Part 3. Financial, Industrial and Communications Strategies for Rehabilitation Technology and the European Commissions TIDE Program, 1992.

5 Young, C. An examination of British assistive technology SMEs and their potential within the Single European Market, the European context for assistive technology. In Proceedings of the 2nd TIDE Congress, 1995, pp. 183-187.

6 Akao, Y. Quality Function Deployment: How to Make QFD Work for You, 1995 (Addison-Wesley, Reading, Massachusetts).

7 Huthwaite, B. Strategic Design: A Guide to Managing Concurrent Engineering, 1995 (Institute for Competitive Design).

8 Prasad, B. Concurrent Engineering Fundamentals: Integrated Product and Process Organisation, 1996, Vol. 1 (PrenticeHall, Englewood Cliffs, New Jersey).

9 Wright, I. Design Methods in Engineering and Product Design, 1998 (McGraw-Hill, London).

10 Pugh, S. Total Design: Integrated Methods for Successful Product Engineering, 1990 (Addison-Wesley, Reading, Massachusetts). 